Delft University of Technology

\title{
Improvement of the Frequency Response Indicators by Optimal UFLS Scheme Settings
}

Acosta, Martha N.; Andrade, Manuel A.; Vázquez, Ernesto; Adiyabazar, Choidorj ; Gonzalez-Longatt, F.; Rueda, J.L.; Palensky, P.

DOI

10.1109/ISIE45063.2020.9152466

Publication date

2020

Document Version

Final published version

Published in

2020 IEEE 29th International Symposium on Industrial Electronics, ISIE 2020 - Proceedings

\section{Citation (APA)}

Acosta, M. N., Andrade, M. A., Vázquez, E., Adiyabazar, C., Gonzalez-Longatt, F., Rueda, J. L., \& Palensky, P. (2020). Improvement of the Frequency Response Indicators by Optimal UFLS Scheme Settings. In 2020 IEEE 29th International Symposium on Industrial Electronics, ISIE 2020 - Proceedings: Proceedings (pp. 1250-1255). [9152466] (IEEE International Symposium on Industrial Electronics; Vol. 2020-June). IEEE . https://doi.org/10.1109/ISIE45063.2020.9152466

Important note

To cite this publication, please use the final published version (if applicable).

Please check the document version above.

\section{Copyright}

Other than for strictly personal use, it is not permitted to download, forward or distribute the text or part of it, without the consent of the author(s) and/or copyright holder(s), unless the work is under an open content license such as Creative Commons.

\section{Takedown policy}

Please contact us and provide details if you believe this document breaches copyrights.

We will remove access to the work immediately and investigate your claim. 
Green Open Access added to TU Delft Institutional Repository

'You share, we take care!' - Taverne project

https://www.openaccess.nl/en/you-share-we-take-care

Otherwise as indicated in the copyright section: the publisher is the copyright holder of this work and the author uses the Dutch legislation to make this work public. 


\section{Improvement of the Frequency Response Indicators by Optimal UFLS Scheme Settings}

\author{
Martha N. Acosta \\ Manuel A. Andrade \\ Ernesto Vázquez \\ School of Mechanical and \\ Electrical Engineering \\ Universidad Autónoma de Nuevo \\ León \\ Nuevo León, México \\ martha.acostamnt@uanl.edu.mx
}

\author{
Choidorj Adiyabazar \\ Power System Analysis and \\ Research Department \\ National Dispatching Center \\ Co.,Ltd \\ Ulaanbaatar, Mongolia \\ choidorj.a@ndc.energy.mn
}

\author{
F. Gonzalez-Longatt \\ Institutt for elektro, IT og \\ kybernetikk \\ Universitetet I Sørøst- \\ Norge \\ Porsgrunn, Norway \\ fglongatt@,fglongatt.org
}

\author{
J.L Rueda and P. Palensky \\ Department of Electrical \\ Sustainable Energy \\ Delft University of Technology \\ (TU Delft) \\ Delft, Netherlands \\ J.L.RuedaTorres@,tudelft.nl
}

\begin{abstract}
This research investigates the positive changes in the system frequency response indicators caused by the implementation of a set of optimal settings of an under-frequency load shedding (UFLS) scheme. The optimal under-frequency load shedding (UFLS) scheme is optimised by minimising the total amount of load shedding and taking into account the recovery process of the system frequency into its operational values after several losses of generation and satisfies the requirements of the under-frequency load shedding standard (PRC-006-SERC-02). The idea of implementing the optimal UFLS scheme is to identify how changes the minimum frequency, minimum time, rate of change of frequency and steady-state frequency when the amount of load shedding change. The optimal UFLS scheme formulation starts with identifying the variables to control with the optimisation and its respective bounds. Then, the objective function is formulated in terms of the total load shedding, and finally, the restrictions and requirements of the systems are written as inequality constraints. The optimal UFLS is evaluated in the IEEE 39-bus system. The simulations results demonstrate the suitability of the optimal UFLS to improve the frequency response indicators.
\end{abstract}

Keywords-frequency stability, optimisation, under-frequency load shedding

\section{INTRODUCTION}

The frequency stability is concerned with the ability of a power system to supply its load after a disturbance involving a generation-load imbalance at a frequency within an acceptable range [1]. The sudden disconnection of large generation units producing a considerable percentage of the total demand in a power system might cause an important power imbalance between the power generation and the load demand. This active power imbalance produces a fast drop in the system frequency generated by the deficit of power supply [2]. If the appropriate control actions are in place, the system frequency must reach an acceptable value after a few seconds. However, if the power imbalance is larger than the designed specification, the frequency can drop to values considered unacceptable or even trip a cascade event putting the power system in risk of instability and subsequent blackout.

To avoid any potential damage of generation units and loadside equipment, it is crucial to precisely control the system frequency within an established, acceptable frequency range or at least, to prevent longer frequency excursions out of this established range. However, if the system frequency reaches unacceptably low values (predefined security threshold), there is a small-time window to implement restorative or emergency actions. If the size of the system frequency disturbance is large, the scheduled power reserve may not be enough to restore the system frequency and the power system operators may use emergency control and protection schemes to maintain power system frequency [3]. An emergency control plan used by years is the well-known under-frequency load shedding (UFLS).

The UFLS strategy is designed so as to balance the demand for electricity with the supply rapidly and to avoid a rapidly cascading power system failure [4]. In simple terms, the UFLS is designed to prevent the system frequency from staying too low for too long by disconnecting the right amount of power loads to regain frequency control. Under-frequency operation is usually more problematic with regard to possible equipment damages than over-frequency operation due to the limited amount of spinning reserves.

The schemes are system protection schemes; it means the scheme objective is the integrity of the system frequency as a whole, in contrast to equipment protections, trying to minimise equipment damages [5]. It is essential to coordinate system under-frequency load shedding with under-frequency protection of the generator. Premature generator tripping, before system load shedding is complete, can lead to unnecessary system collapse.

A real example of frequency stability problems and the actions of UFLS is the famous Italian blackout of 28 September 2003 (see Fig. 1). During the frequency event, the frequency dropped down to $49 \mathrm{~Hz}$, due to the loss of power infeed coming from the central interconnected European power system. The frequency continued dropping until it reaches the underfrequency threshold of $47.5 \mathrm{~Hz}$ in the next 150 seconds [6], all generation units were tripped according to the predefined UFLS scheme. However, the main reason for the blackout was that during this terminal phase of the frequency collapse the undervoltage load shedding (UVLS) did not appropriately compensate the additional loss of generation coming from around $7.5 \mathrm{GW}$ of distributed power plants tripped during underfrequency operation [7]. The Italian blackout of 28 September 
2003 made clear the need to redefine the load shedding plan in Italy in order to appropriately handle the loss of imported power or the power plants operating on the distribution grid.

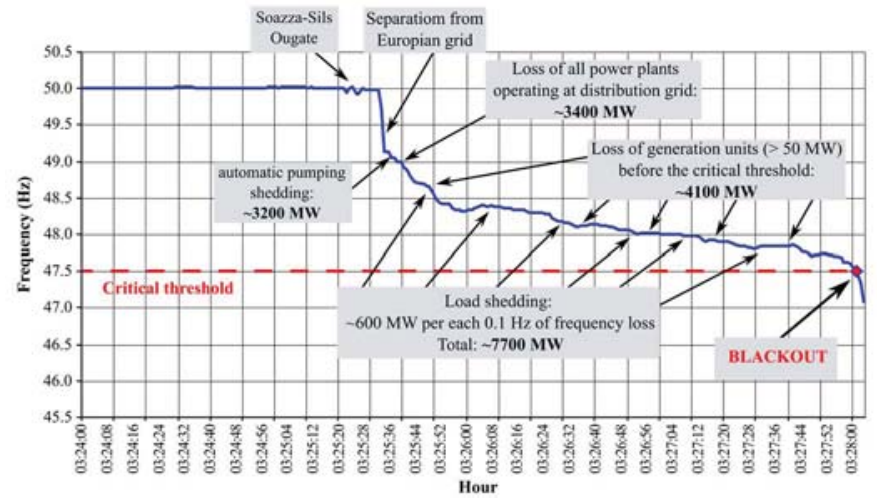

Fig. 1. Plot of the frequency behaviour during the transitory frequency event in Italy 28 September 2003 [6].

The major frequency event in Italy of 28 September 2003 made evident the importance of an appropriate UFLS. However, the situation of frequency control and stability and the problem of adequate settings of UFLS is becoming more and more complicated with the increased penetration levels of power converted based generation technologies (reducing the total system rotational inertia) [8].

The primary objective of UFLS schemes is to arrest frequency dropping in due time by shedding an appropriate amount of load, in order to recover the frequency into its nominal values [9]. Ideally, the UFLS must act as the primary option and by doing so, preventing the action of generation-side under-frequency protections, which would finally lead to a cascading power outage [10]. In the traditional UFLS schemes, the settings of the UFLS relays are mainly based on the power system operator's knowledge of the power system performance during major frequency events. However, although the frequency is recovered into its nominal values, the UFLS settings are not optimal, and they end up disconnecting more load than necessary.

The main propose of this research paper is to investigate the positive changes in the system frequency response indicators caused by the implementation of an optimal setting of a UFLS scheme. An optimal calculation process of the settings of the UFLS improves the power system reliability by minimising the unnecessary excessive load shedding and prevent the operation of under-frequency protections of the synchronous generator. However, this research paper introduces the problem of optimal settings of UFLS relayed using mathematical optimisation. Then, the methodology is used to set the UFLS on a test system, and the ulterior motive is to determinate how the optimal stings impact the frequency response indicators: minimum frequency, minimum time, rate of change of frequency and steady-state frequency.

This paper is organised as follows: in Section II, it is described the methodology to calculate the optimal UFLS scheme such as the selected variables to be controlled by the optimisation, the objective function formulation, and the constraints. Section III presents a description of the test system that is used to evaluate the optimal UFLS scheme. Moreover, three cases are presented for assessing the UFLS scheme. Section IV describes the results obtained and present the main observations of the results. Finally, Section V presents the conclusion.

\section{OPTIMAL UFLS SCHEME FORMULATION}

The frequency load shedding (FLS) is an emergency control strategy dedicated to mitigating substantial mismatch between the generation and the loads. The UFLS is dedicated specifically to deal with under frequency events where there is a lack of generation or an excess of power demand. Load shedding is becoming a very attractive research topic in recent time to deal with several problems related to extremally reduced inertia scenarios, the market pressure to minimise the reserve margins and the operating the tie-line near to the limit of capacities.

Many different approaches are reported for implementing UFLS settings are detailed in the scientific literature: traditional schemes, artificial intelligence techniques, and more recently, meta-heuristic optimisation algorithms. A summary of those methods is beyond the scope of this paper but [10] provides a compressive and relative new overview.

\section{A. Frequency Response indicators}

The system frequency response (SFR) of a power system is typically analysed by using time-domain plots of the system frequency when the major event is applied (typically a sudden generation disconnection). The principal frequency response indicators are represented in Fig. 2, and they are defined as follows [4]-[12-13]:

- The minimum frequency $\left(f_{\min }\right)$ denotes the minimum value that the frequency reaches during the transient response when the major event is applied.

- The minimum time $\left(t_{\min }\right)$ is the time required from the instant where a disturbance is started until the frequency reaches its minimum value.

- The Rate of Change of Frequency $(R o C o F)$ represents the speed of change of frequency $(d f)$ concerning with the time change $(d t)$, i.e. $R o C o F=d f / d t[\mathrm{~Hz} / \mathrm{s}]$.

- The steady-state frequency $\left(f_{s s}\right)$ refers to the value at which the frequency is positioned after the transient response and at which the $R o C o F$ is zero. This value can be interpreted as the capability of the power system of recovering after a disturbance.

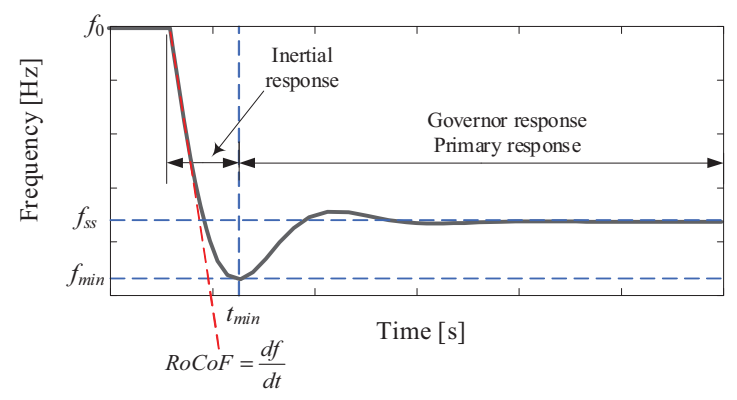

Fig. 2. Representation of the principal frequency response indicators in a classical SFR signal. 


\section{B. UFLS Settings}

UFLS relays are adopted to protect the system by shedding some of the system load to keep the frequency of the system close to the nominal value.

UFLS relays can be classified into two categories[11]: (i) Fixed number of stages and time delays and (ii) Adaptative number of stages and variable shed demands. The traditional UFLS relay (such as ANSI 81L) falls in the first category and is extensively used in power systems. In this research paper, the UFLS relays are considered to have a fixed number of stages, but the setting will be optimised in the next subsections. Traditional UFLS scheme relies basically on four main settings:

- Block size of dropped load: (percentage or power unit) It defines the block size of load shedding is the size of load to be dropped at all stages.

- Number of load shedding stages: (integer) Load shedding is usually implemented on stages. It defines the number of steps to be used to shed the load.

- Frequency threshold: (typically in Hertz) It defines a pre-set frequency level at each stage in which load must be shed.

- Time delay for each stage. (seconds or cycles) It defines the time delay between activating the consecutive stages.

\section{Optimisation Problem Definition}

The process to formulate the optimal UFLS scheme followed in this paper is based in the following steps: First, the appropriate set of control variables are identified, those variables are selected in order to control the frequency response following a system frequency disturbance at the time the optimisation considered the main aspects of the UFLS relay features and respective bounds are defined for the relay settings. Then, the objective function to be minimised was written in terms of the control variables. Finally, the restrictions and requirements of the systems are written as inequality constraints. The full procedure of each step is described below.

\section{1) Variables}

The control vector $(\mathbf{x})$ is a vector used to specify the control variables to be used in the optimisation process:

$$
\mathbf{x}=\left[\begin{array}{lll}
\Delta P_{i j} & f_{s p, j}^{1} \quad \Delta f_{s p, k j}
\end{array}\right]^{\mathrm{T}},\left\{\begin{array}{l}
i=1, \ldots, N_{S} \\
j=1, \ldots, N_{R} \\
k=1, \ldots, N_{S}-1
\end{array}\right.
$$

where $\Delta P_{i j}$ is the percentage load shedding of the $i$-th stage in the $j$-th UFLS relay, $f_{s p, i j}^{1}$ is the first frequency set-point of the $j$-th UFLS relay and $\Delta f_{s p, k j}$ represents the interval between two subsequent frequency set-points. Moreover, $N_{\mathrm{R}}$ is the number of UFLS relays installed in the power system, and $N_{\mathrm{S}}$ is the number of load shedding stages in each relay.

The control variables are bounded by its upper $(u)$ and lower (l) allowable values as follows:

$$
\begin{aligned}
& \Delta P_{l} \leq \Delta P_{i j} \leq \Delta P_{u} \\
& f_{s p, l}^{1} \leq f_{s p, j}^{1} \leq f_{s p, u}^{1} \\
& \Delta f_{s p, l} \leq \Delta f_{s p, k j} \leq \Delta f_{s p, u}
\end{aligned}
$$

where $\Delta P_{l}$ and $\Delta P_{u}$, represents the maximum and minimum permissible percentage of load shedding, respectively. $f_{s p, l}^{1}$ and $f_{s p, u}^{1}$ are the maximum and minimum limit frequency setpoint in the first stage, respectively. Moreover, $\Delta f_{s p, l}$ and $\Delta f_{s p, u}$ are the maximum and minimum values that can take $\Delta f_{s p}$.

\section{2) Objective function}

In this paper, the idea of optimising the settings of the UFLS relay is to reduce as much as possible the power demand interrupted during the under-frequency event. As a consequence, the purpose of the UFLS optimisation is determinate the minimum amount of load shed required to recovers the steadystate frequency into its operating values. Therefore, the objective function is formulated as the sum of all active stages in each UFLS relay multiplied by active power in its respective load. The objective function is:

$$
\min \left(\sum_{j=1}^{N_{R}} \sum_{i=1}^{n_{S}} \Delta P_{i j} P_{j}\right)
$$

where $P_{j}$ is the active power of the $j$-th load with UFLS relay and $n_{S}$ is the number of activated stages. $n_{s}$ is different from $N_{s}$ $\left(n_{s} \leq N_{s}\right)$.

\section{3) Constraints}

The objective function defined in (3) is subject to certain restrictions to ensure the security of the power system and fulfil the technical requirements of the utility companies:

a) Steady-state frequency $\left(f_{s s}\right)$ : after a massive loss of generation, the $f_{s s}$ must remain inside the operating range of the synchronous generators, i.e., $f_{s s}^{\min } \leq f_{s s} \leq f_{s s}^{\max }$. This restriction is formulated as two inequality constraints as follow

$$
f_{s s}-f_{s s}^{\max } \leq 0
$$

and

$$
f_{s s}^{\min }-f_{s s} \leq 0
$$

b) Frequency set-point $\left(f_{s p}\right)$ : the $\mathrm{f}_{\mathrm{sp}}$ in each stage of the UFLS relays shall be inside the limits defined by the technical requirements of the utility companies, i.e., $f_{s p}^{\min } \leq f_{s p} \leq f_{s p}^{\max }$. Since the optimisation gives the first $f_{\mathrm{sp}}$ of each relay and it is already bounded, it is necessary to define the inequality constraint for the minimum limit as follows:

$$
f_{s p}^{\min }-f_{s p, i j} \leq 0
$$

\section{STUDY CASE}

To investigates the positive changes in the system frequency response indicators caused by the implementation of an optimal setting of a UFLS scheme, a classical and well-known tests system is used: the IEEE 39-bus system. The IEEE 39 bus system is well known as ten machines New-England Power 
System. Generator 1 represents the aggregation of a large number of generators. The original model data come from the book titled "Energy Function Analysis for Power System Stability" [12]. The test system has been implemented in DIgSILENT $^{\circledR}$ PowerFactory ${ }^{\mathrm{TM}} 2020$. The schematic single line diagram of the test system is shown in Fig. 3. The test system consists of ten generators, 19 loads, 34 transmission lines, 12 transformers and 39 buses. The total active power generation is 6,140.81 MW, and the total power demand is 6097.10 MW [13].

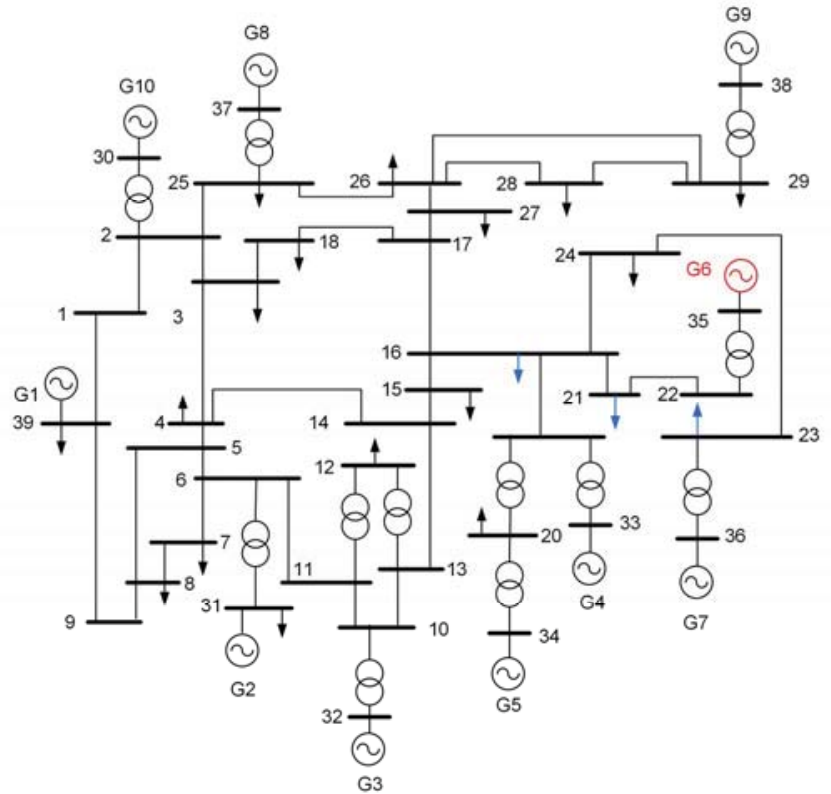

Fig. 3. Illustrative single-line diagram of the IEEE-39 bus system. UFLS relays have been installed in buses 16, 21 and 22 (noted in the diagram). Frequency disturbance is the sudden disconnection of G6 (highlighted).

The SFR of the test system is excited by a system frequency event, in this very specific case, the sudden disconnection of G6 at $t=1.0$ second, which represents a loss of $10.585 \%$ of the total generation, $\Delta \mathrm{P}=P_{G 6}$. The UFLS relays are installed near to generator G6 in Load 16, Load 21 and Load 23. In this paper, the three UFLS relays $\left(N_{R}=3\right)$ has four load shedding stages $\left(N_{S}=4\right)$. The time delay was set as $t_{d}=0.20 \mathrm{~s}$. The generator causing the disturbance (G6) is highlighted with red colour, and the loads where the UFLS relays are installed are marked with blue colour in Fig. 3.

In this paper, three simulation cases are considered: Case I refers to the natural SFR of the test system without any UFLS scheme. Case II study the SFR of the test system considering the UFLS but using a traditional setting. Finally, Case III represents the SFR of the tests system but considering the optimal settings of the UFLS is presented in Section II. The three defined cases considering the time delay as $t_{d}=0.20 \mathrm{~s}$, four load shedding stages $\left(N_{S}=4\right)$ and the same disturbance, $\Delta \mathrm{P}=650 \mathrm{MW}$.

The Improved Harmony Search (IHS) metaheuristic algorithm is applied to solve the UFLS optimisation problem. Details of the IHS algorithm are described in [14]. For all cases, it is observed the indicators of the frequency response: (i) minimum frequency $\left(f_{\min }\right)$, (ii) minimum time $\left(t_{\text {min }}\right)$, (iii) the maximum $R o C o F$ and (iv) steady-state frequency $\left(f_{s s}\right)$.
As the test system is representative of the North American system, the parameters of the UFLS relays must satisfy the SERC (South-eastern Electric Reliability Council) UFLS Standard: PRC-006-SERC-02 [15]:

- $f_{s s}$ shall be kept within the continuous operating range of the generating units between $59.5 \mathrm{~Hz}$ and $60.5 \mathrm{~Hz}$. Therefore, $f_{s s}$ is bounded as $59.5 \leq f_{s s} \leq 60.5$.

- The highest value of $f_{s p}$ shall be no lower than $59.3 \mathrm{~Hz}$ and not higher than $59.5 \mathrm{~Hz}$. Moreover, the lowest value of $f_{s p}$ shall be no lower than $58.4 \mathrm{~Hz}$. Therefore, $f_{s p}$ is bounded as $58.4 \leq f_{s p} \leq(59.5-59.3)$.

- $\Delta f_{s p}$ shall be at least $0.2 \mathrm{~Hz}$ but no greater than $0.5 \mathrm{~Hz}$, i.e., $0.2 \leq \Delta f_{s p} \leq 0.5$.

- The time delay $\left(t_{d}\right)$ for the high-speed trip shall be at least six cycles, i.e., $0.1 \mathrm{~s} \leq t_{d}$.

Case I (Case Base): In this case, it is presented the dynamic response of the frequency when the disturbance occurs by outage the generator G6, and there is not a UFLS scheme installed. Fig. 4 shows the frequency response measured in all buses. The minimum frequency is $f_{\min }=57.923 \mathrm{~Hz}$ at $t_{\min }=$ $29.582 \mathrm{~s}$, and it is presented in bus 39 .

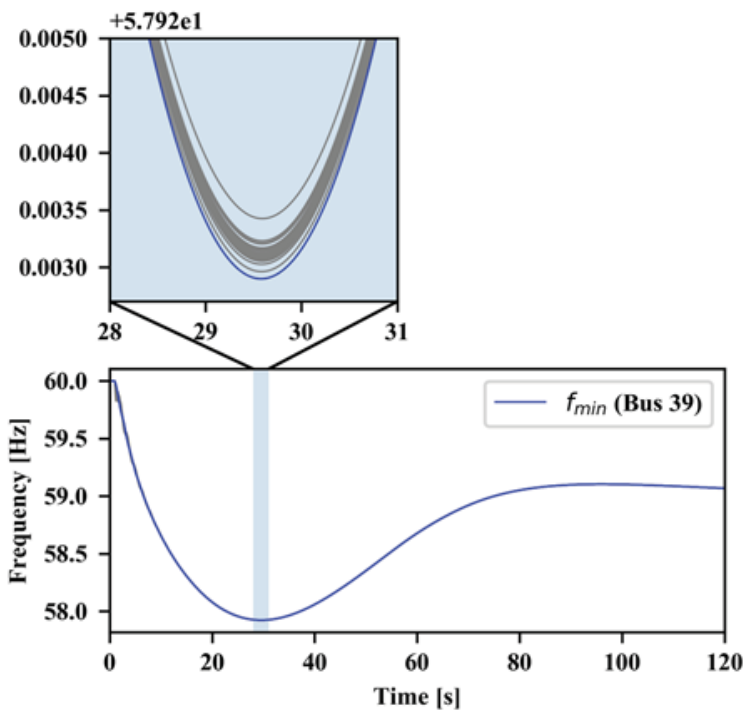

Fig. 4. Frequency response in the 39 buses after the outage of generator G6 Case I.

Fig. 5 shows the $\mathrm{RoCoF}$ of all buses, the maximum $\mathrm{RoCoF}$ produced by the disconnection of G6 is presented in bus 36 and its value is $R o C o F_{\max }=-2.565 \mathrm{~Hz} / \mathrm{s}$ at $1.012 \mathrm{~s}$.

The steady-state frequency for Case I is $f_{s s}=59.024 \mathrm{~Hz}$, and it is evident that the power system requires a UFLS scheme to recover the frequency into the established $f_{s s}$ limits, i.e., $59.5 \leq$ $f_{s s} \leq 60.5$. Moreover, the under-frequency relays of the synchronous generators, in $60 \mathrm{~Hz}$ nominal frequency, typically operates if the frequency reach vales from $58.4 \mathrm{~Hz}$ to 57.9 and the frequency does not recover within 30 seconds [16]. Therefore, another reason to install the UFLS scheme is to avoid the activation of the under-frequency relays that protect the synchronous generators since, in this case, $f_{\min }$ reaches values below $58 \mathrm{~Hz}$. 


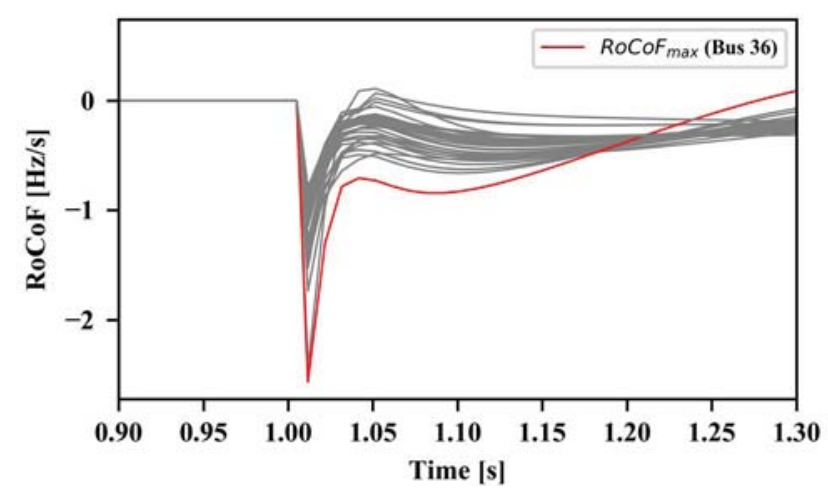

Fig. 5. RoCoF response in the 39 buses after the outage of generator G6: Case I.

Case II (Traditional UFLS scheme): This case presents the frequency response when a traditional UFLS scheme is implemented on the IEEE-39 bus system in Load 16, Load 21 and Load 23. The settings of the installed UFLS relays are chosen in order to fulfil the requirements of the SERC UFLS Standard. The settings are presented in Table I.

TABLE I. UFLS RELAYS SETTINGS USING THE TRADITIONAL UFLS SCHEME

\begin{tabular}{c|c|c|c|c}
\hline \hline Stage & $\Delta P(\%)$ & $f_{s p}(\mathrm{~Hz})$ & $\Delta f_{s p}(\mathrm{~Hz})$ & $t_{d}(\mathrm{~s})$ \\
\hline 1 & 30 & 59.3 & 0.3 & 0.2 \\
2 & 25 & 59 & 0.3 & 0.2 \\
3 & 25 & 58.7 & 0.3 & 0.2 \\
4 & 20 & 58.4 & 0.3 & 0.2 \\
\hline
\end{tabular}

Case III (Optimal UFLS scheme): shows the frequency response when the optimal UFLS scheme is used to obtain the parameters of the UFLS relays previously installed in Load 16, Load 21 and Load 23.

The settings obtained from the optimal UFLS scheme are described in Table II, it can be observed that the settings are for the first stage of all relays and only the second stage of the relay in Load 23. These results mean that it is only required to activate those stages in order to ensure the frequency recovering. Furthermore, it is given the frequency set-point of each stage and those values satisfy the constraint defined in (6).

TABLE II. UFLS RELAYS SETTINGS USING THE OPTIMAL UFLS SCHEME

\begin{tabular}{c|c|c|c|c|c|c}
\hline \hline \multirow{2}{*}{ Stage } & \multicolumn{2}{|c|}{ Load 16 } & \multicolumn{2}{c|}{ Load 21 } & \multicolumn{2}{c}{ Load 23 } \\
\cline { 2 - 7 } & $\Delta P(\%)$ & $f_{s p}(\mathrm{~Hz})$ & $\Delta P(\%)$ & $f_{s p}(\mathrm{~Hz})$ & $\Delta P(\%)$ & $f_{s p}(\mathrm{~Hz})$ \\
\hline 1 & 32.690 & 59.339 & 22.566 & 59.311 & 46.868 & 59.416 \\
2 & --- & --- & --- & --- & 8.225 & 59.146 \\
3 & --- & --- & --- & --- & --- & --- \\
4 & --- & --- & --- & --- & --- & --- \\
\hline
\end{tabular}

The convergence curve of the objective function defined in (3) after being evaluated 300 times is presented in Fig. 6. It is observed from generation 230 the value of the objective function remains constant; this indicates that the objective function reaches its minimum value and fulfil the constraints defined in Section II.C.3) by (4), (5) and (6) .

\section{RESULTS AND DISCUSSION}

The dynamic simulation of the IEEE-39 bus system to evaluate the three cases defined above are presented in this section. The frequency response of Case I, Case II and Case III is shown in Fig. 7. In this figure, it can be observed the changes in the frequency response depending on whether or not there is installed a UFLS scheme.

Case II improve the frequency response by reducing the $f_{\text {min }}$, $t_{\min }$ and recovering the steady-state frequency inside the established operating values. Moreover, it showed how it is improved the frequency response when it is optimised the total load shedding in Case III, the minimum frequency and minimum time is minimised and the steady-state frequency remains inside the established operating values.

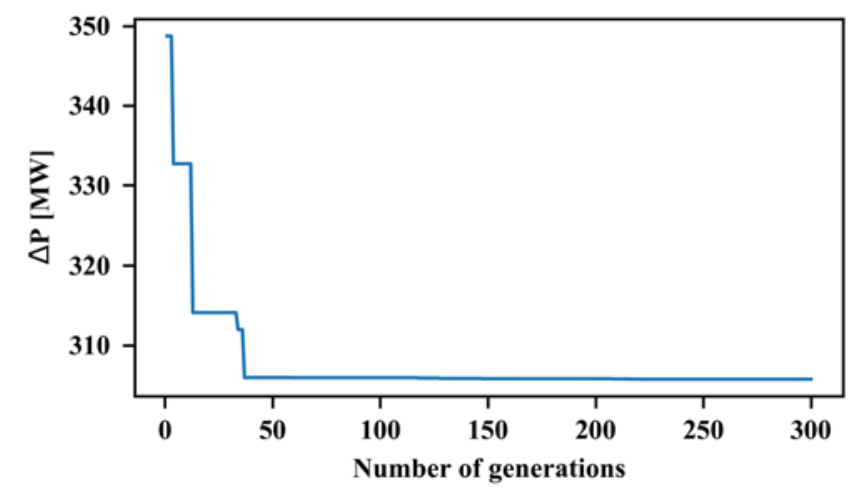

Fig. 6. Convergence curve of the optimal UFLS scheme. Case III.

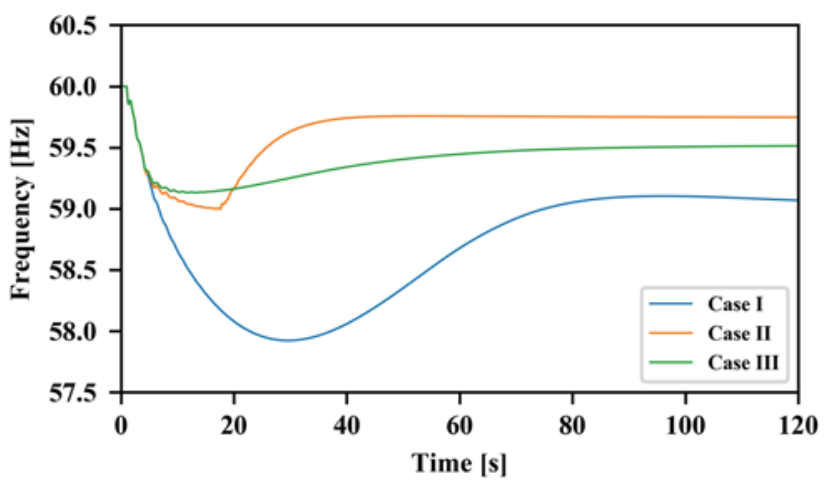

Fig. 7. Frequency response for Case I, Case II and Case III after the outage of generator G6.

The frequency response indicators and the total load shedding are summarised in Table III.

TABLE III. FREQUENCY RESPONSE INDICATORS AND TOTAL LOAD SHEDDING FOR THE THREE CASES

\begin{tabular}{c|c|c|c|c|c}
\hline \hline Case & $\begin{array}{c}f_{\min } \\
(\mathrm{Hz})\end{array}$ & $\begin{array}{c}t_{\min } \\
(\mathrm{s})\end{array}$ & $\begin{array}{c}R o C_{0} F_{\max } \\
(\mathrm{Hz} / \mathrm{s})\end{array}$ & $\begin{array}{c}f_{s s} \\
(\mathrm{~Hz})\end{array}$ & $\begin{array}{c}\Delta P \\
(\mathrm{MW})\end{array}$ \\
\hline I & 57.923 & 29.582 & -2.565 & 59.024 & ---- \\
II & 58.999 & 17.665 & -2.565 & 59.746 & 463.925 \\
III & 59.130 & 11.618 & -2.565 & 59.521 & 305.736 \\
\hline
\end{tabular}

From Table III, the frequency response indicators after the disconnection of generator G6 are discussed. In Case I, the frequency reaches its minimum value at $29.582 \mathrm{~s}$, and its steady- 
state operation value is $59.024 \mathrm{~Hz}$, this frequency value is outside of the established $f_{s s}$ limits. The maximum $R o C o F$ after the disturbance is $-2.565 \mathrm{~Hz} / \mathrm{s}$. Since in this case there is not installed a UFLS scheme, there are no actions to arrest the frequency decaying. In contrast, when the UFLS scheme is implemented, the frequency responds indicators depend on the UFLS relays settings. In Case II, the minimum frequency and minimum time are reduced $1.85 \%$ and $40.28 \%$, respectively concerning Case I. Furthermore, the stages activated for all UFLS relays are Stage 1 and Stage 2, and the load shedding is $463.925 \mathrm{MW}$ which represents $7.61 \%$ of the total load. Thus, the steady-state frequency is improved and is $59.746 \mathrm{~Hz}$.

Meanwhile, the settings for the UFLS relays obtained from Case III decreases the values of the minimum frequency and minimum time in $2.08 \%$ and $60.72 \%$, respectively in contrast to Case I. In this case, Stage 1 activated for all UFLS relays, and Stage 2 is just activated in the relay installed in Load 23. Moreover, the load shedding is $305.736 \mathrm{MW}$, which represents $5.01 \%$ of the total load, and it decreases $34.01 \%$ whit respect Case II. Furthermore, the steady-state frequency remains inside the established limits, and its value is $59.521 \mathrm{~Hz}$.

\section{CONCLUSIONS}

The principal conclusion in this research paper is that the optimal settings in the UFLS scheme prevent an unnecessary load shedding since it is observed a decreeing in the total load shedding concerning with the traditional UFLS scheme. Moreover, it is identified that the impact of minimising the total amount of load shedding is directly reflected in the frequency response indicators, and thus these indicators were improved.

The minimum frequency value as well as the minimum time value decrease when the optimal UFLS scheme is implemented in contrast with the traditional UFLS scheme. Moreover, the steady-state frequency in both cases is recovered inside predefined values. Furthermore, the maximum $\mathrm{RoCoF}$ is not modified by the presence of UFLS scheme and is not impacted by the amount of load shedding.

\section{ACKNOWLEDGEMENT}

Ms Martha N. Acosta would like to acknowledge the financial support given by CONACYT (México), and the support of University of South-Eastern Norway and Universidad Autónoma de Nuevo León. Prof F. Gonzalez-Longatt would like to express his gratitude to DIgSILENT $\mathrm{GmbH}$ for supporting his research.

\section{REFERENCES}

[1] P. Kundur et al., "Definition and Classification of Power System Stability IEEE/CIGRE Joint Task Force on Stability Terms and Definitions," IEEE Trans. Power Syst., vol. 19, no. 3, pp. 1387-1401, Aug. 2004.

[2] F. Gonzalez-Longatt, "Impact of synthetic inertia from wind power on the protection/control schemes of future power systems: Simulation study," in IET Conference Publications, 2012, vol. 2012, no. 593 CP.

[3] H. Bevrani, Robust Power System Frequency Control, Second Edi. Cham: Springer International Publishing, 2014.

[4] F. Gonzalez-Longatt;, F. Sanchez;, and Rujiroj Leelaruji, "Unveiling the Character of the Frequency in Power Systems," in IEEE-PES GTD Grand International Conference \& Exposition Asia 2019 (IEEE-PES GTD Asia 2019), 2019.

[5] IEEE, IEEE Std C37.117 - IEEE Guide for the Application of Protective Relays Used for Abnormal Frequency Load Shedding and Restoration, no. August. 2007.

[6] UCTE, Final Report of the Investigation Committee on the 28 September 2003 Blackout in Italy, no. 1. 2004.

[7] S. Corsi and C. Sabelli, "General blackout in Italy sunday September 28, 2003, h. 03:28:00,” in 2004 IEEE Power Engineering Society General Meeting, 2004, vol. 2, pp. 1691-1701.

[8] F. Sanchez and F. Gonzalez-Longatt, "Optimization of Frequency Controller Parameters of a BESS by considering Rate of Change Constraints," in 2019 IEEE Milano PowerTech, Powertech 2019, 2019.

[9] Y. R. Omar, I. Z. Abidin, S. Yusof, H. Hashim, and H. A. Abdul Rashid, "Under Frequency Load Shedding (UFLS): Principles and implementation," in PECon2010 - 2010 IEEE International Conference on Power and Energy, 2010, pp. 414-419.

[10] L. Sigrist, L. Rouco, and F. M. Echavarren, "A review of the state of the art of UFLS schemes for isolated power systems," Int. J. Electr. Power Energy Syst., vol. 99, no. September 2017, pp. 525-539, 2018.

[11] Y. Y. Hong and P. H. Chen, "Genetic-based underfrequency load shedding in a stand-alone power system considering fuzzy loads," IEEE Trans. Power Deliv., vol. 27, no. 1, pp. 87-95, Jan. 2012.

[12] M. A. Pai, Energy Function Analysis for Power System Stability. Springer US, 1989.

[13] P. Wall, F. Gonzalez-Longatt, and V. Terzija, "Estimation of generator inertia available during a disturbance," in IEEE Power and Energy Society General Meeting 2012, 2012, pp. 1-8.

[14] M. Mahdavi, M. Fesanghary, and E. Damangir, "An improved harmony search algorithm for solving optimization problems," Appl. Math. Comput., vol. 188, no. 2, pp. 1567-1579, May 2007.

[15] "PRC-006-SERC-02:Automatic Underfrequency Load Shedding Requirements - NERCipedia." [Online]. Available: https://nercipedia.com/active-standards/prc-006-serc-02automaticunderfrequency-load-shedding-requirements/. [Accessed: 25-Jan2020].

[16] H. Seyedi and M. Sanaye-Pasand, "Design of New Load Shedding Special Protection Schemes for a Double Area Power System," Am. J. Appl. Sci., vol. 6, no. 2, pp. 317-327, Feb. 2009. 